\title{
Effect of the Synthesis Route on the Microstructure and the Dielectric Behavior of $\mathrm{CaCu}_{3} \mathrm{Ti}_{4} \mathrm{O}_{12}$ Ceramics
}

\author{
Miguel A. de la Rubia,
}

Pilar Leret Jose de Frutos, and José F. Fernández
$\mathrm{CaCu}_{3} \mathrm{Ti}_{4} \mathrm{O}_{12}$ (CCTO) was prepared by a conventional synthesis (CS) and through reaction sintering, in which synthesis and sintering of the material take place in one single step. The microstructure and the dielectric properties of CCTO have been studied by XRD, FE-SEM, EDS, AFM, and impedance spectroscopy to correlate structure, microstructure, and electrical properties. Samples prepared by reactive sintering show very similar dielectric behavior to those prepared by CS. Therefore, it is possible to prepare CCTO by means of a single-step processing method.

\section{Introduction}

$\mathrm{R}$ ECENTLY, the compound $\mathrm{CaCu}_{3} \mathrm{Ti}_{4} \mathrm{O}_{12}$ (CCTO) has attracted much interest due to its high dielectric constant (up to $10^{5}$ ), which is almost frequency-independent up to $10^{6} \mathrm{~Hz}$, and shows good temperature stability in the range between $100 \mathrm{~K}$ and $400 \mathrm{~K}$. ${ }^{1}$ The main disadvantage of this material is the high dielectric losses that limit its use. Although materials with very high dielectric constant are generally ferroelectric or relaxor, CCTO is centrosymmetric in the temperature range under study, and it does not present phase transition. The system presents distorted cubic perovskite structure with an $\operatorname{Im} 3$ space group and a lattice parameter of $7.391 \AA$. The $\mathrm{TiO}_{6}$ octahedron is tilted and, as a consequence, the coordination of $\mathrm{Ca}$ and $\mathrm{Cu}$ cations is altered, producing a square planar arrangement of the oxygen around the $\mathrm{Cu}^{2+}$ cations and a 12-coordinate icosahedral environment for $\mathrm{Ca}^{2}$

The origin of the high dielectric constant of CCTO is still a source of controversy. Intrinsic effects such as stoichiometric changes, oxygen vacancies, $\mathrm{Cu}$ segregation and different oxidation states of $\mathrm{Ti}$ and $\mathrm{Cu}$ could result in high dielectric constant via extrinsic effects related to the microstructure, as stated by the Internal Barrier Layer Capacitance (IBLC) model. According to this model, the material can be considered as an ensemble of $n$-type semiconducting CCTO grains and insulating barriers, corresponding to a very thin $\mathrm{Cu}$-rich secondary phase observed at the grain boundary. ${ }^{3,4}$ This characteristic microstructure with semiconducting grains and insulating barriers (including domain boundaries and grain boundaries) results in electrostatic barriers at the grain boundaries, which are responsible for the nonlinear currentvoltage behavior that this material presents. Oxygen vacancies may be proposed as a possible cause for the electron for- mation. $^{5}$ At room temperature, dc resistivity of undoped CCTO is principally determined by the grain boundary resistivity and therefore this resistivity depends on processing. There are very few reports related to the impurity effect on CCTO. In CCTO ceramics, a clear increase of the dielectric constant has been observed with sintering time due to the incorporation of the $\mathrm{Cu}$-rich grain boundary secondary phase into the CCTO grains. 6

The electrical properties of both doped and undoped CCTO depend as much on the raw materials as on processing. ${ }^{7}$ Reaction sintering method has never before been used to prepare CCTO.

The aim of this work was to study $\mathrm{CaCu}_{3} \mathrm{Ti}_{4} \mathrm{O}_{12}$ ceramics prepared by reaction sintering without an intermediate calcination step, and to compare these materials with the ones prepared by a conventional synthesis method.

\section{Experimental Procedure}

Ceramic samples of $\mathrm{CaCu}_{3} \mathrm{Ti}_{4} \mathrm{O}_{12}$ were prepared by two different synthesis routes: the conventional solid-state reaction (CS) and by means of reaction sintering (RS). In all cases, $\mathrm{TiO}_{2}$ powder (anatase, 99.9\%, Merck, $d_{50}=0.5 \mu \mathrm{m}$; Darmstadt, Germany), $\mathrm{CuO}\left(99.9 \%\right.$, Aldrich, $d_{50}=3.3 \mu \mathrm{m}$; Madrid, Spain), and $\mathrm{CaCO}_{3}$ (Aldrich, $d_{50}=0.9 \mu \mathrm{m}$ ) were mixed in attrition mill for $3 \mathrm{~h}$ with zirconia balls using de-ionized water and $0.3 \mathrm{wt} \%$ of Dolapix C64 as dispersant. The milled powders were dried and sieved through $100 \mu \mathrm{m}$ mesh.

Conventional solid state reaction consisted of the calcination at $900^{\circ} \mathrm{C}-12 \mathrm{~h}$ of the milled mixture of raw materials in adequate amounts (synthesis of CCTO). Then the CS synthesized powder was attrition milled for $3 \mathrm{~h}$ (after milling $\left.d_{50}=0.8 \mu \mathrm{m}\right)$. Dry powders were pressed into disks of $8 \mathrm{~mm}$ in diameter and $1.3 \mathrm{~mm}$ in thickness at $200 \mathrm{MPa}$ by using $0.6 \mathrm{wt} \%$ of polyvinyl alcohol PVA and $0.3 \mathrm{wt} \%$ of polyethylene glycol PEG as organic binders to favor the pressing step. The disks were sintered at $1100^{\circ} \mathrm{C}-32 \mathrm{~h}$. In the reaction sintering method, RS, the synthesis and sintering of CCTO pellets were carried out in the same step at $1100^{\circ} \mathrm{C}$ for $32 \mathrm{~h}$. All thermal treatments were carried out with a heating and cooling rate of $3^{\circ} \mathrm{C} / \mathrm{min}$. The density of the samples for both synthesis routes after sintering was $\geq 4.8 \mathrm{~g} / \mathrm{cm}^{3}(>95 \%$ of the theoretical density). Samples prepared by reaction sintering shrunk $\sim 6 \%$ more in diameter than conventional synthesis ones. X-ray diffraction analysis was performed on a diffractometer X'Pert PRO of Panalytical using $\mathrm{CuK} \alpha 1$ radiation. RS samples were polished and thermally etched at $1000^{\circ} \mathrm{C}$ for $5 \mathrm{~min}$. The microstructure was observed by using a Hitachi SEM TM-1000 (Krefeld, Germany). To perform the electrical characterization, polished parallel disks were electroded with Pt by sputtering with a DSC-050 of BALTEC (Wetzlar, Germany). Dielectric characterization was measured at RT in the range $10^{-2} \mathrm{~Hz}-1 \mathrm{MHz}$ in a Solartron 1296 dielectric interface (Hampshire, UK). 


\section{Results and Discussion}

Figure 1 shows the XRD pattern of the CS powder calcined at $900^{\circ} \mathrm{C}-12 \mathrm{~h}$. For a better analysis of the spectra, the logarithmic scale has been used, resolving the noise of the spectra and provoking the enlargement of minor peaks that in linear scale are not easily detected. XRD analysis of the calcined powder shows the presence of the perovskite CCTO phase without traces of secondary phases or unreacted raw materials. XRD analysis of the sintered CCTO samples (Fig. 2) shows that, regardless of the processing method CS or RS, only the perovskite CCTO phase is identified. The sintering of CS samples occurs in solid state because there is no $\mathrm{TiO}_{2}$ nor $\mathrm{CuO}$ unreacted raw materials available, to develop the eutectic liquid around $1000^{\circ} \mathrm{C}^{8}$ that assists sintering. However, in RS, the elimination of the calcination step allows a

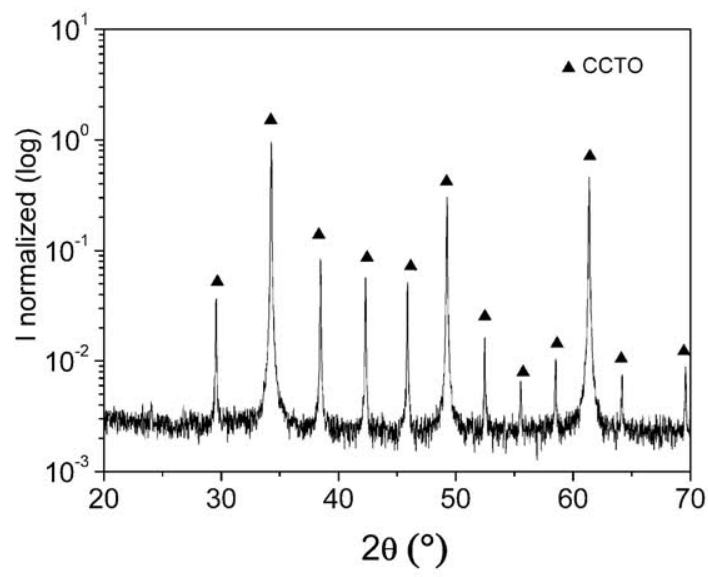

Fig. 1. XRD of raw material calcined at $900^{\circ} \mathrm{C}-12 \mathrm{~h}$.
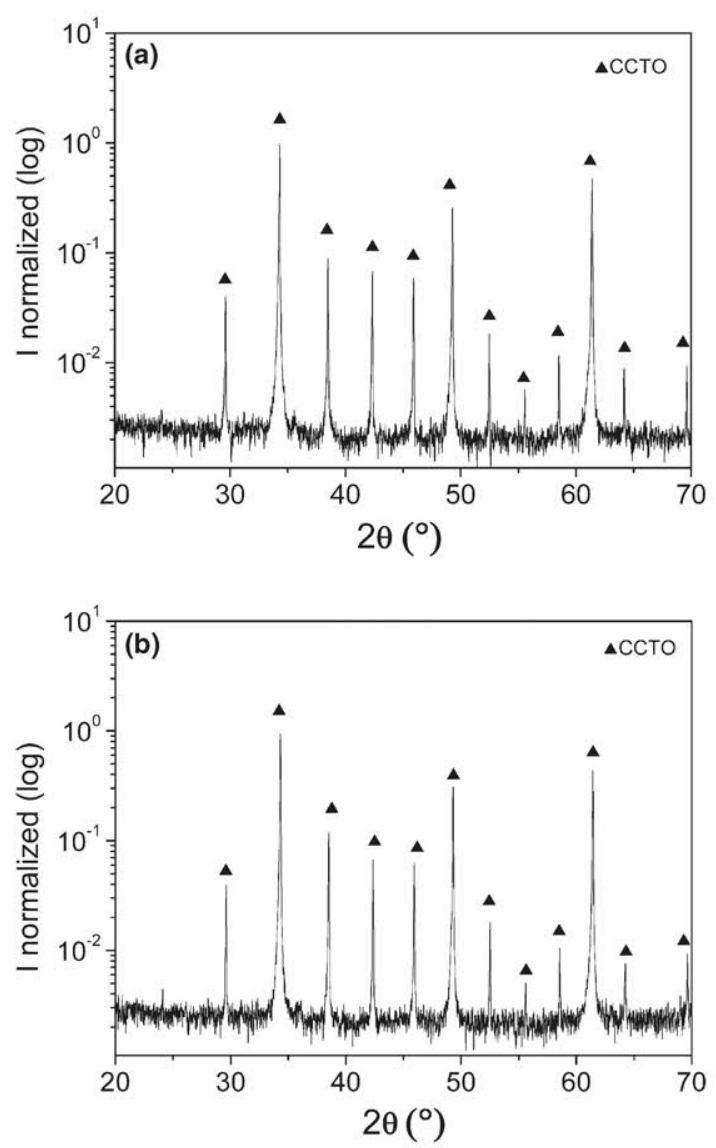

Fig. 2. XRD of sintered CCTO samples. (a) CS and (b) RS. possible reaction between $\mathrm{CuO}$ and $\mathrm{TiO}_{2}$ at high temperature $\left(\sim 1000^{\circ} \mathrm{C}\right)$ to form the eutectic liquid that can assist the first steps of sintering.

The SEM characterization of polished and thermally etched samples shows similar microstructures for both synthesis routes (Fig. 3). Sintered samples from both routes show a bimodal grain size microstructure that is slightly more marked in the CS sample. In the CS sample, there are regions of small grains with thick $\mathrm{Cu}$-rich intergranular phase; however, in RS samples, some grain boundaries have a very thin $\mathrm{Cu}$-rich secondary phase (Fig. 4). The $\mathrm{Cu}$-rich secondary phase recrystallizes in the grain boundary during the thermal etching treatment, and it is identified by XRD analysis (Fig. 5). The large amount of secondary phase observed in the microstructure of Fig. 3 is associated with a surface effect, in agreement with other authors. ${ }^{9}$ Prakash and Varma ${ }^{9}$ indicated that there is a preferential segregation of the $\mathrm{Cu}$-rich phase on the surface due to inhomogeneous distribution of oxygen on the surface and in the interior of the sample. This $\mathrm{Cu}$-rich phase disappears thinning out a few layers from the top and the bottom surfaces. For a better observation of the microstructure, the samples were thermically etched, favoring the segregation and recrystallization of the $\mathrm{Cu}$-rich phase over the surface of the samples. Moreover, other microstructural features of CCTO as domain boundaries are very sensitive to the etching thermal treatment according to literature. ${ }^{10,11}$ In the same way, Guillemet-
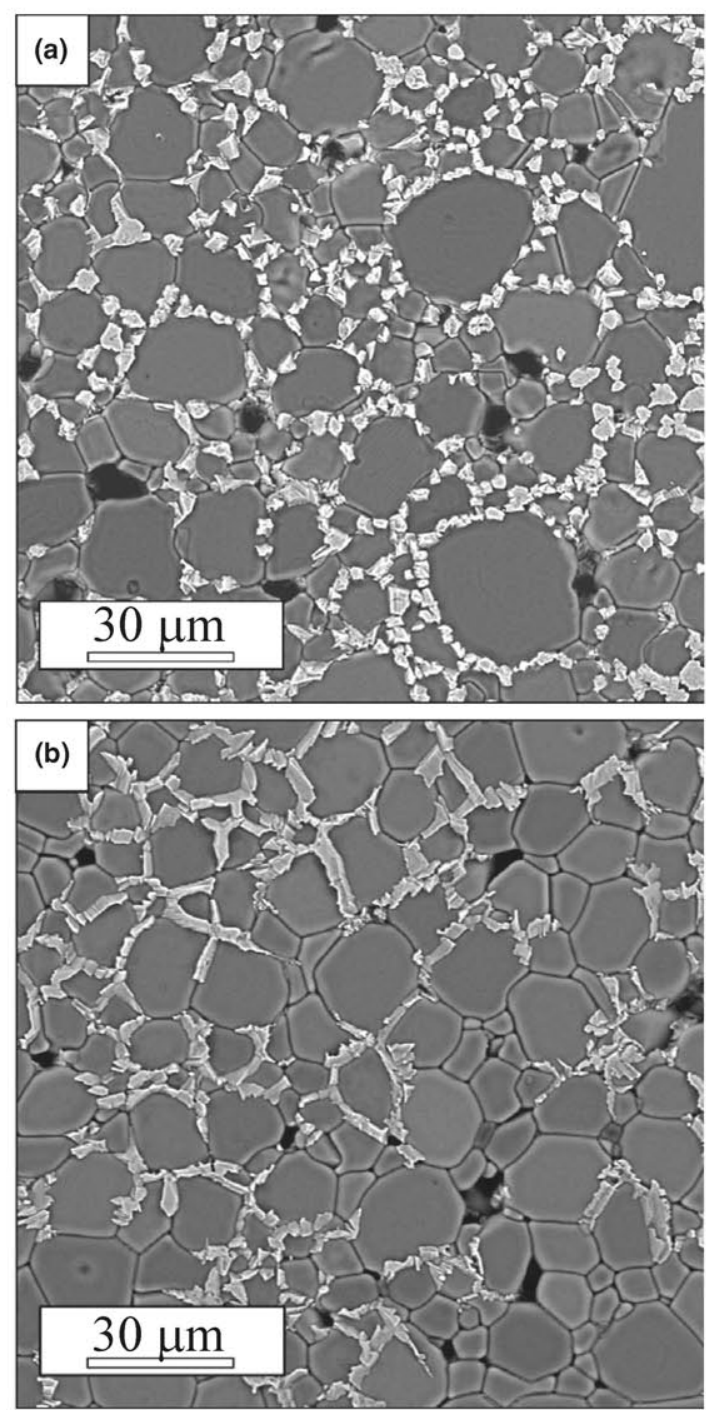

Fig. 3. SEM images of the CCTO samples polished and thermally etched. (a) CS and (b) RS. 

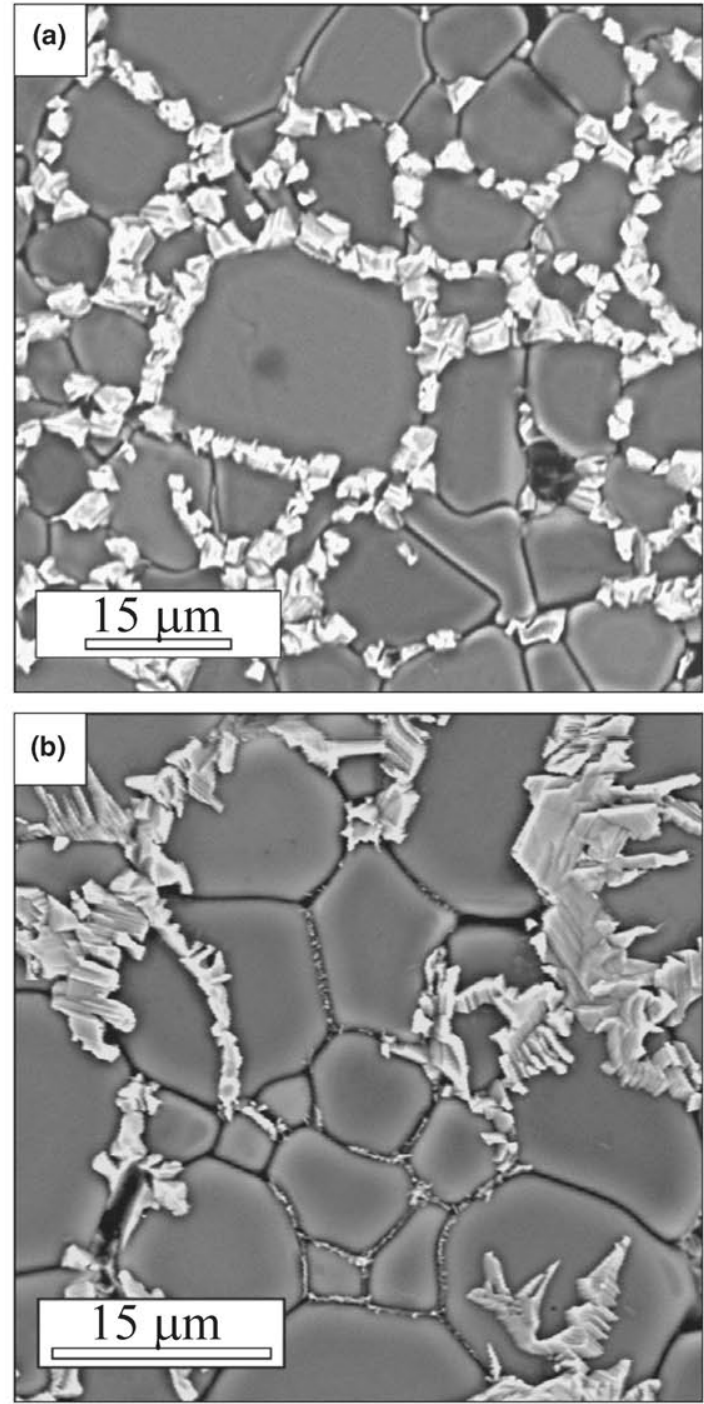

Fig. 4. SEM micrographs of the $\mathrm{Cu}$-rich intergranular phase in CCTO samples polished and thermally etched. (a) CS and (b) RS.

Fritsch et al. ${ }^{12}$ show microstructures with a large and thick amount of $\mathrm{Cu}$-rich secondary phase and a very high dielectric response.

Table I summarizes the RT impedance characteristics of CCTO samples. Grain and grain boundary resistance are considered as the intercept of the bulk $(\mathrm{g})$ and grain boundary $(\mathrm{gb})$ semicircles, respectively, with the real part of the impedance. Using the relationship $2 \pi f_{\max } R_{\mathrm{g}} C_{\mathrm{g}}=1$ and $2 \pi f_{\max } R_{\mathrm{gb}} C_{\mathrm{gb}}=1$ at the impedance semicircle maximum, the $C \mathrm{~g}$ and $C \mathrm{gb}$ values were obtained. $\mathrm{Z}^{\prime}-\mathrm{Z}^{\prime \prime}$ plots for $\mathrm{CS}$ and RS samples (Fig. 6a) apparently show only one semicircle corresponding to the insulating grain boundary region, but if we compare the semicircle shape in the different frequency regions, we can consider several arc superpositions. More than one arc can fit the data related to interfacial relaxation phenomena (Maxwell-Wagner-Sillars) associated with different grain boundaries. The semicircles do not intercept the $Z^{\prime}$ axis in cero at high frequency, and these resistances correspond to the semiconducting grain regions, $(R \mathrm{~g} \sim 35 \Omega$ and $27 \Omega$ ) for CS an RS samples, respectively (Fig 6b). These values are in agreement with the one reported by Adams et al. ${ }^{13}$ The semicircles assigned to the grain boundary regions showed higher impedance 0.56 and $1.2 \mathrm{M} \Omega$, for CS and RS samples, respectively. Capacitance values associated with grain boundaries for CS and RS are $9.1 \times 10^{-9}$ and $2.7 \times 10^{-8} \mathrm{~F}$, respectively. Figures $7 \mathrm{a}$ and $\mathrm{b}$ show the relative dielectric constant $\left(\varepsilon_{\mathrm{r}}\right)$ and the dielectric losses $(\tan \delta)$ in
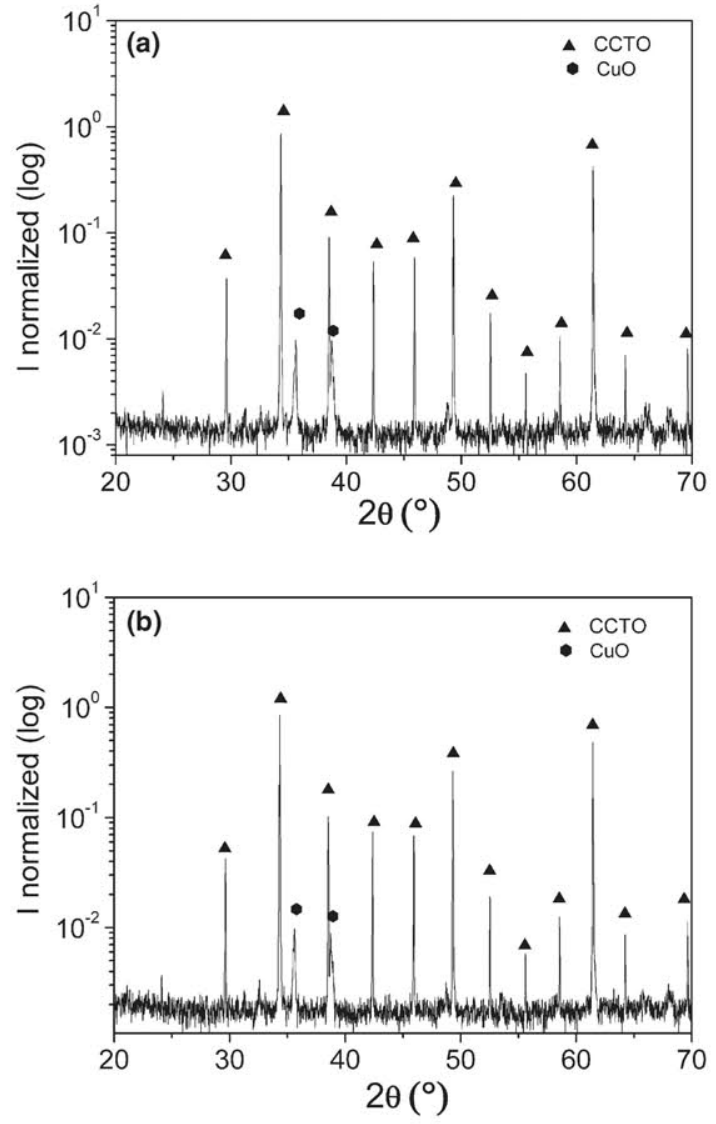

Fig. 5. XRD of sintered, polished, and thermally etched CCTO ceramics samples. (a) CS and (b) RS.

Table I. Resistance $(\Omega)$ and Capacitance (F) Values for Grains and Grain Boundaries of the Different Samples Prepared by Both Synthesis Routes

\begin{tabular}{llllll}
\hline & \multicolumn{2}{c}{$\mathrm{R}(\Omega)$} & & \multicolumn{2}{c}{$\mathrm{C}(\mathrm{F})$} \\
\cline { 2 - 3 } \cline { 5 - 6 } Sample & Grain & Grain boundary & & Grain & Grain boundary \\
\hline CS & 35 & $5.6 \times 10^{5}$ & & - & $9.1 \times 10^{-9}$ \\
RS & 27 & $1.2 \times 10^{6}$ & & - & $2.7 \times 10^{-8}$ \\
\hline
\end{tabular}

a wide frequency range for both processing methods. The dielectric constant and losses show slight differences in the dielectric behavior in the frequency range between $10^{5}$ and $10^{1} \mathrm{~Hz}$ such as the dielectric constant for RS sample possesses higher frequency dependence. The dielectric losses for RS samples show lower frequency dependence in this frequency range. Both characteristics decrease with the frequency increase. At high frequency values $\left(10^{2}-10^{6} \mathrm{~Hz}\right)$, the dielectric constant for the RS sample is slightly higher than for the CS one; both are almost frequency-independent, exhibiting the same tendency as the real component of the permittivity, $\varepsilon^{\prime}$, which is associated with capacitive phenomena. In this frequency range, relative permittivity $\left(\varepsilon_{\mathrm{r}}\right)$ values for RS and CS samples are approximately $6.6 \times 10^{4}$ and $2.6 \times 10^{4}$, respectively (Fig. 7a). These values are comparable to the ones previously reported in the literature. ${ }^{12,14,15}$ Dielectric losses are low $\left(\sim 10^{-1}\right)$ and slightly higher for the RS sample than for the CS one, although the RS sample shows lower dependence of the frequency (Fig. 7b). At lower frequencies $\left(<10^{2} \mathrm{~Hz}\right)$, the dielectric constant for CS sample is slightly higher than for the RS one, although it is accompanied by higher dielectric losses (Figs. 7a and b). This behavior follows the same trend as the one exhibited by the imaginary component of the permittivity, $\varepsilon^{\prime \prime}$, related to 

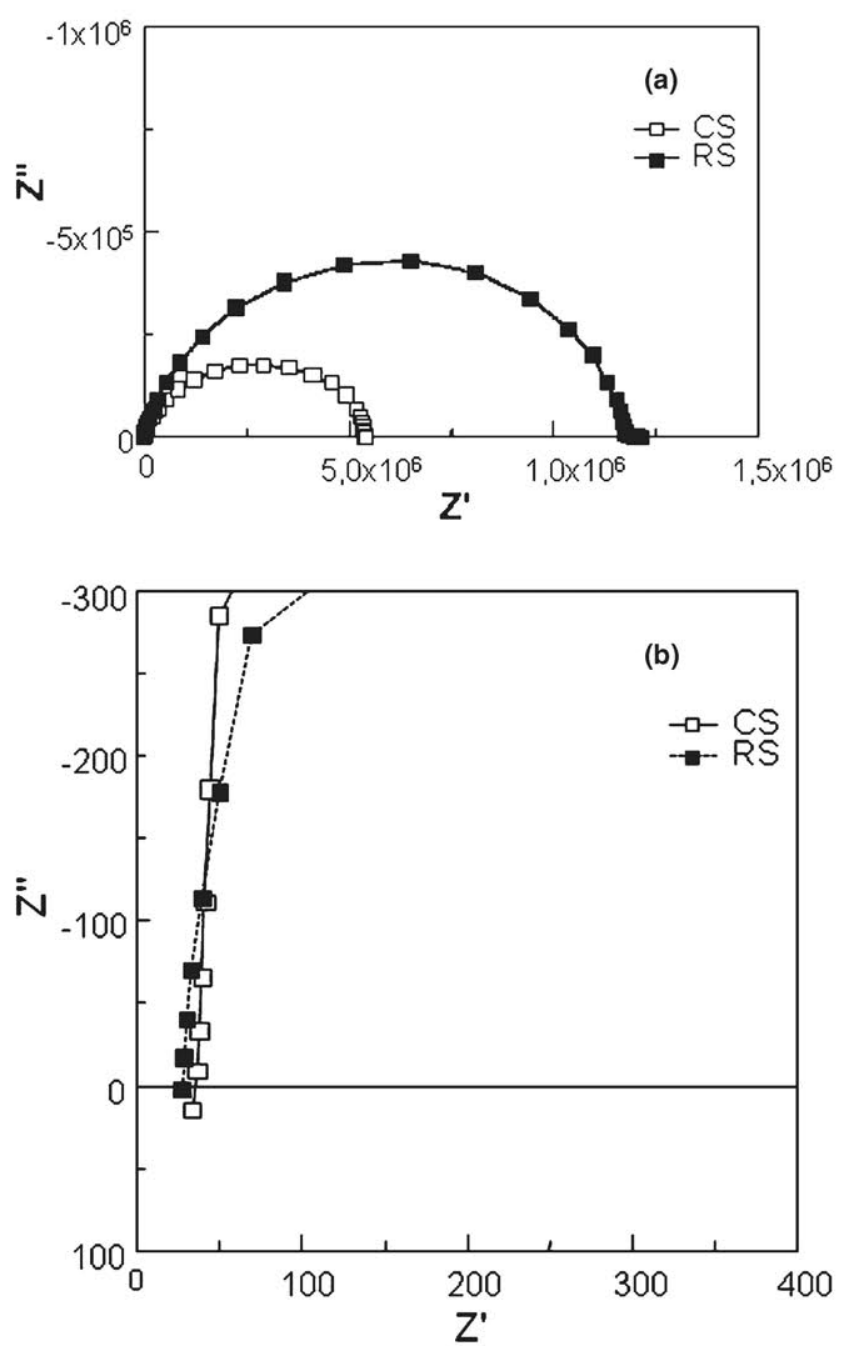

Fig. 6. $Z^{\prime}-Z^{\prime \prime}$ plots for sintered CCTO samples for different processing methods. (a) All frequencies range and (b) Zoom of the high frequency.

conductive phenomena. From $10^{2}$ to $10^{6} \mathrm{~Hz}$, the grain's interior dominates the electrical response with high $\varepsilon$ values between $6.6 \times 10^{4}$ and $2.6 \times 10^{4}$, and at lower frequencies $\left(10^{-2}-10^{0} \mathrm{~Hz}\right)$, the giant dielectric response $\left(10^{8}-10^{6}\right)$ of CCTO ceramics is associated with conduction processes that occur in the grain boundary region, although it is accompanied by high dielectric losses $\left(10^{3}-10^{1}\right){ }^{16}$ According to complex impedance analysis, the grain's interior dominates the electrical response at high frequencies $\left(\sim 10^{6} \mathrm{~Hz}\right)$, but the dielectric behavior in all the frequency range is related to interfacial relaxation phenomena. This relaxation known as Maxwell-Wagner-Sillars is due to the displacement of the trapped charge in the interfaces that is development in heterogeneous dielectric materials such as CCTO, associated with grain boundaries and in agreement with the IBLC model. When phases of a ceramic have different conductivities such as in CCTO, imposition of an electric field causes the movement of charge from the more conductive phase toward the less conductive one. ${ }^{17}$ At lower frequencies $\left(10^{-2}-1 \mathrm{~Hz}\right)$, an increase in the dielectric constant that takes place may be assigned to the space charge interfacial polarization effects. The high dielectric constant at low frequencies is accompanied by very high dielectric losses. The dielectric loss is considerably higher especially at low frequencies, which is mainly attributed to inhomogeneous conduction vis-à-vis interfacial polarization. ${ }^{18}$ The copper-rich liquid phase during the sintering process probably favors the grain-shell wetting, leading to multilayered materials where the charge carriers' concentration at the different interfaces rises as the copper
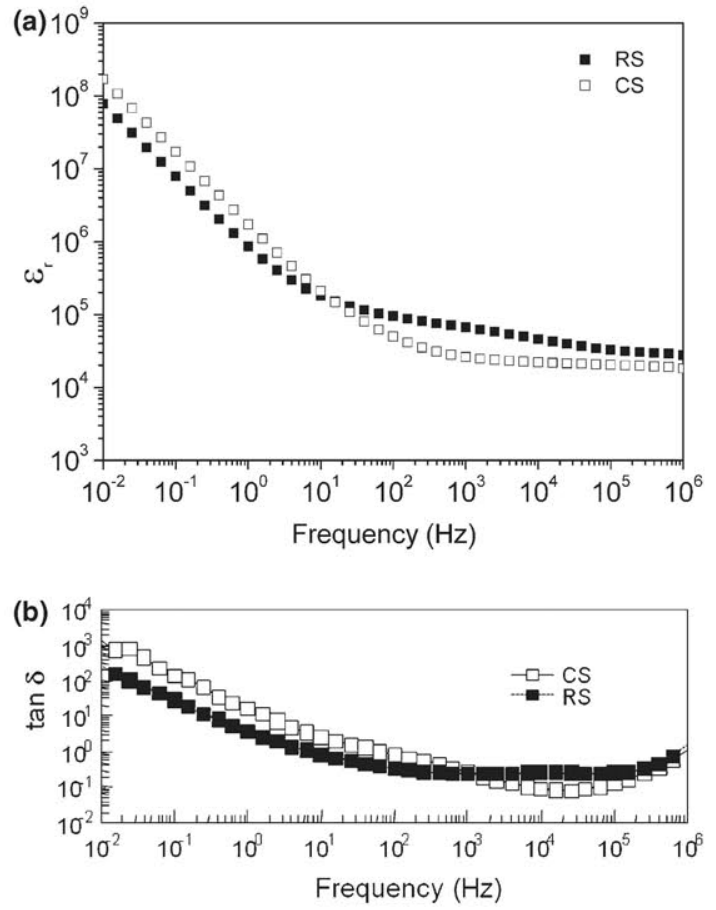

Fig. 7. (a) Frequency dependence of dielectric constant ( $\varepsilon$ ) and (b) dielectric loss of CCTO samples for both synthesis routes (RS, reaction sintering; $\mathrm{CS}$, conventional synthesis).

amount increases. Charge accumulation on both sides of the boundary layers provokes an increase in the dielectric constant of the samples accompanied by an increase in the dielectric losses. Other authors suggest that the dielectric losses increase is associated with a pure conduction mechanism described by the $\sigma / \omega \varepsilon_{\mathrm{o}}$ ratio. ${ }^{12}$ In the same manner, at lower frequencies, conduction losses due to space charge relaxation, which usually result in the increase in the dielectric constant, become relevant. Nonhomogeneous materials like porous materials, polycrystalline or with a lot of defects can show at the lowest frequencies an increase in the real part of the dielectric constant. This effect also takes place in heterogeneous materials composed of two or more phases. ${ }^{19}$

Based on these results and the microstructural characterization, it can be deduced that the dielectric response is closely related to the microstructure and the $\mathrm{Cu}$-rich intergranular phase. According to the IBLC model, ${ }^{12,13,15,20}$ the effective dielectric constant $\left(\varepsilon_{\mathrm{eff}}\right)$ is directly proportional to the average grain size $\left(t_{\mathrm{g}}\right)$ and inversely proportional to the grain boundary thickness $\left(t_{\mathrm{gb}}\right)$ as $\varepsilon_{\mathrm{eff}}=\varepsilon_{\mathrm{r}}\left(t_{\mathrm{g}} / t_{\mathrm{gb}}\right)$ where $\varepsilon_{\mathrm{r}}$ is the relative permittivity. Samples obtained by both processing methods (CS and RS) show similar microstructures (bimodal grain size with similar amount of $\mathrm{Cu}$-rich secondary phase in grain boundaries), although they show slight differences in the dielectric behavior in the frequency range between $10^{5}$ and $10^{1} \mathrm{~Hz}$ such as the dielectric constant for RS samples possesses higher frequency dependence. Both samples are in agreement with the IBLC model, where the resistance of the grain is lower than the grain boundary one (Table I). According to this model and in agreement with the obtained results, the sample that shows higher dielectric (RS) is the one in which the differences in conduction between grain and grain boundaries are higher (Table I). Point out that the samples obtained by both processing methods show very high dielectric constants accompanied by low dielectric losses in a wide frequency range $(102 \mathrm{~Hz}-1 \mathrm{MHz})$.

\section{Conclusions}

Samples prepared by both processing methods CS (conventional synthesis) and RS (reaction sintering) show similar 
microstructures (bimodal grain size with similar amount of $\mathrm{Cu}$-rich secondary phase in grain boundaries), although they show slight differences in the dielectric behavior in the frequency range between $10^{5}$ and $10^{1} \mathrm{~Hz}$ such as the dielectric constant for RS samples possesses higher frequency dependence. In this frequency range, the sample that shows that higher dielectric constant (RS) is the one in which the differences in conduction between grain and grain boundaries are higher in agreement with the IBLC model. In both samples, the very high dielectric response is accompanied by low dielectric losses, exhibiting the same trend as the real component of the permittivity, $\varepsilon^{\prime}$, which is associated with capacitive phenomena. At lower frequencies $\left(<10^{1} \mathrm{~Hz}\right)$, the giant dielectric constant for CS sample is slightly higher than the RS one, although it is accompanied by higher dielectric losses. This behavior follows the same trend as the one exhibited by the imaginary component of the permittivity $\varepsilon^{\prime \prime}$ related to conductive phenomena. It has been possible to obtain $\mathrm{CaCu}_{3} \mathrm{Ti}_{4} \mathrm{O}_{12}$ ceramics with very high dielectric constant by means of reaction sintering and therefore without an intermediate calcination step. This is the first time that CCTO ceramics are prepared in a single step, performing synthesis and sintering in only one thermal treatment.

\section{Acknowledgments}

This work has been financially supported by the Spanish Ministry of Science and Innovation under the program MAT2010-21088-C03-01 and 02

\section{References}

${ }^{1}$ M. A. Subramanian, D. Li, N. Duan, B. A. Reisner, and A. W. Sleight, "High Dielectric Constant in ACu3Ti4O12 and $\mathrm{ACu}_{3} \mathrm{Ti}_{3} \mathrm{FeO}_{12}$ Phases," $J$ Solid State Chem., 151 [2] 323 (2000).

${ }^{2}$ B. Bochu, M. N. Deschizeaux, J. C. Joubert, A. Collomb, J. Chenavas, and M. Marezio, "Synthèse et Caractèrisation d"une Série de Titanates Perovskites Isotypes de $\mathrm{CaCu}_{3} \mathrm{Mn}_{4} \mathrm{O}_{12}$," J. Solid State Chem., 29, 291-8 (1979).

${ }^{3}$ J. F. Fernández, P. Leret, J. Frutos, M. A. de la Rubia, M. S. Martín-González, J. L. Costa Kramer, J. L. G. Fierro, A. Quesada, and M. A. García, "Proof for co-Existence of two Magnetic Contributions in Pure and Doped $\mathrm{CaCu}_{3} \mathrm{Ti}_{4} \mathrm{O}_{12}$ Giant Dielectric Constant Ceramics," J. Am. Ceram. Soc., 92 [10] $2311-8$ (2009).
${ }^{4}$ P. Leret, J. Fernandez, J. de Frutos, and D. Fernandez- Hevia, "Nonlinear I-V Behaviour of Doped $\mathrm{CaCu}_{3} \mathrm{Ti}_{4} \mathrm{O}_{12}$ Ceramics," J. Eur. Ceram. Soc., 27, 3091-905 (2007).

${ }^{5}$ D. C. Sinclair, T. B. Adams, F. D. Morrison, and A. R. West, "One Step Internal Barrier Layer Capacitor," Appl. Phys. Lett., 80 [12] 2153-5 (2002).

${ }^{6}$ J. J. Romero, P. Leret, F. Rubio-Marcos, A. Quesada, and J. Fernandez, "Evolution of the Intergranular Phase During Sintering of $\mathrm{CaCu}_{3} \mathrm{Ti}_{4} \mathrm{O}_{12}$ Ceramics," J. Eur. Ceram. Soc., 30 [3] 737-42 (2010).

${ }^{7}$ P. Leret, M. A. de la Rubia, F. Rubio-Marcos, J. J. Romero, and J. F. Fernández, "Effect of Processing on the Sintering of High Dielectric Constant $\mathrm{CaCu}_{3} \mathrm{Ti}_{4} \mathrm{O}_{12}$ Ceramics," Int. J. Appl. Ceram. Technol., 8, 1201-7 (2011).

${ }^{8}$ M. A. de la Rubia, P. Leret, J. J. Reinosa, J. J. Romero, J. de Frutos, and J. F. Fernandez, "Experimental Determination of the Eutectic Temperature in Air of the CuO-TiO 2 Pseudobinary System," J. Eur. Ceram. Soc., 32 [1] 71-6 (2012).

${ }^{9}$ B. S. Prakash and K. B. R. Varma, "Influence of Sintering Conditions and Doping on the Dielectric Relaxation Originating From the Surface Layer Effects in $\mathrm{CaCu}_{3} \mathrm{Ti}_{4} \mathrm{O}_{12}$ Ceramics," J. Phys. Chem. Solids, 68, 490-502 (2007).

${ }^{10}$ T. T. Fang and H. K. Shiau, "Mechanism for Developing the Boundary Barrier Layers of $\mathrm{CaCl}_{3} \mathrm{Ti}_{4} \mathrm{O}_{12}, " J$. Am. Ceram. Soc., 87 [11] 2072-9 (2004).

${ }^{11}$ T. T. Fang and C. P. Liu, "Evidence of the Internal Domains for Inducing the Anomalously High Dielectric Constant of $\mathrm{CaCu}_{3} \mathrm{Ti}_{4} \mathrm{O}_{12}$," Chem. Mater., 17, 5167-71 (2005).

${ }^{12}$ S. Guillemet-Fritsch, T. Lebey, M. Boulos, and B. Durant, "Dielectric Properties of $\mathrm{CaCu}_{3} \mathrm{Ti}_{4} \mathrm{O}_{12}$ Based Multiphased Ceramics," J. Eur. Ceram. Soc., 26, 1245-57 (2006).

${ }^{13}$ T. B. Adams, D. C. Sinclair, and A. R. West, "Tnfluence of Processing Conditions on the Electrical Properties of $\mathrm{CaCu}_{3} \mathrm{Ti}_{4} \mathrm{O}_{12}$ Ceramics," J. Am. Ceram. Soc., 89 [10] 3129-35 (2006).

${ }^{14}$ L. Liu, H. Fan, X. Chen, and P. Fang, "Electrical Properties and Microstructural Characteristics of Nonstoichiometric $\mathrm{CaCu}_{3 \mathrm{x}} \mathrm{Ti}_{4} \mathrm{O}_{12}$ Ceramics," J. Alloys Compd., 469, 529-34 (2009).

${ }^{5}$ M. Pan and B. A. Bender, "A Bimodal Grain Size Model for Predicting the Dielectric Constant of Calcium Copper Titanate Ceramics," J. Am. Ceram. Soc., 88, 2611-4 (2005)

${ }^{16}$ P. Leret, M. A. de la Rubia, J. J. Romero, J. de Frutos, and J. F. Fernandez, "Phenomenological Model of Grain Boundary Behaviour Under a Bias Field in Nb-Doped $\mathrm{CaCu}_{3} \mathrm{Ti}_{4} \mathrm{O}_{12}$ Ceramics," J. Alloy. Compd., 509 [41] 971923 (2011).

${ }^{17}$ R. C. Buchanan, Ceramic Materials for Electronics Processing, Properties and Applications, p. 114, Crc. Press, New York, 1991

${ }^{18}$ P. Thomas, S. Satapathy, K. Dwarakanath, and K. B. R. Varma, "Dielectric Properties of Poly(Vinylidene Fluoride) $/ \mathrm{CaCu}_{3} \mathrm{Ti}_{4} \mathrm{O}_{12}$ Nanocrystal Composite Thick Films," Express Polym. Lett., 4 [10] 632-43 (2010).

${ }^{19}$ J. M. Albella and J. M. Martin, Physics of Dielectrics. Chap. 5-6, Ed. Marcombo, Barcelona, 1984.

${ }^{20}$ A. J. Moulson and J. M. Herbert Electroceramics: "Materials, Properties and Applications." Chapman and Hall, London, UK, 1990. 